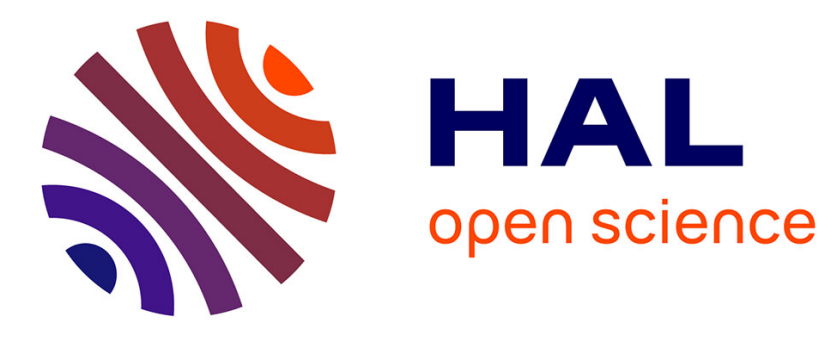

\title{
Unstable Plasmoids in Dusty Plasma Experiments
}

\author{
Maxime Mikikian, Hagop Tawidian, Thomas Lecas
}

\section{To cite this version:}

Maxime Mikikian, Hagop Tawidian, Thomas Lecas. Unstable Plasmoids in Dusty Plasma Experiments. IEEE Transactions on Plasma Science, 2014, 42, pp.2670. 10.1109/TPS.2014.2326459 . hal01053533

\section{HAL Id: hal-01053533 \\ https://hal.science/hal-01053533}

Submitted on 31 Jul 2014

HAL is a multi-disciplinary open access archive for the deposit and dissemination of scientific research documents, whether they are published or not. The documents may come from teaching and research institutions in France or abroad, or from public or private research centers.
L'archive ouverte pluridisciplinaire HAL, est destinée au dépôt et à la diffusion de documents scientifiques de niveau recherche, publiés ou non, émanant des établissements d'enseignement et de recherche français ou étrangers, des laboratoires publics ou privés. 


\title{
Unstable Plasmoids in Dusty Plasma Experiments
}

\author{
Maxime Mikikian, Hagop Tawidian and Thomas Lecas
}

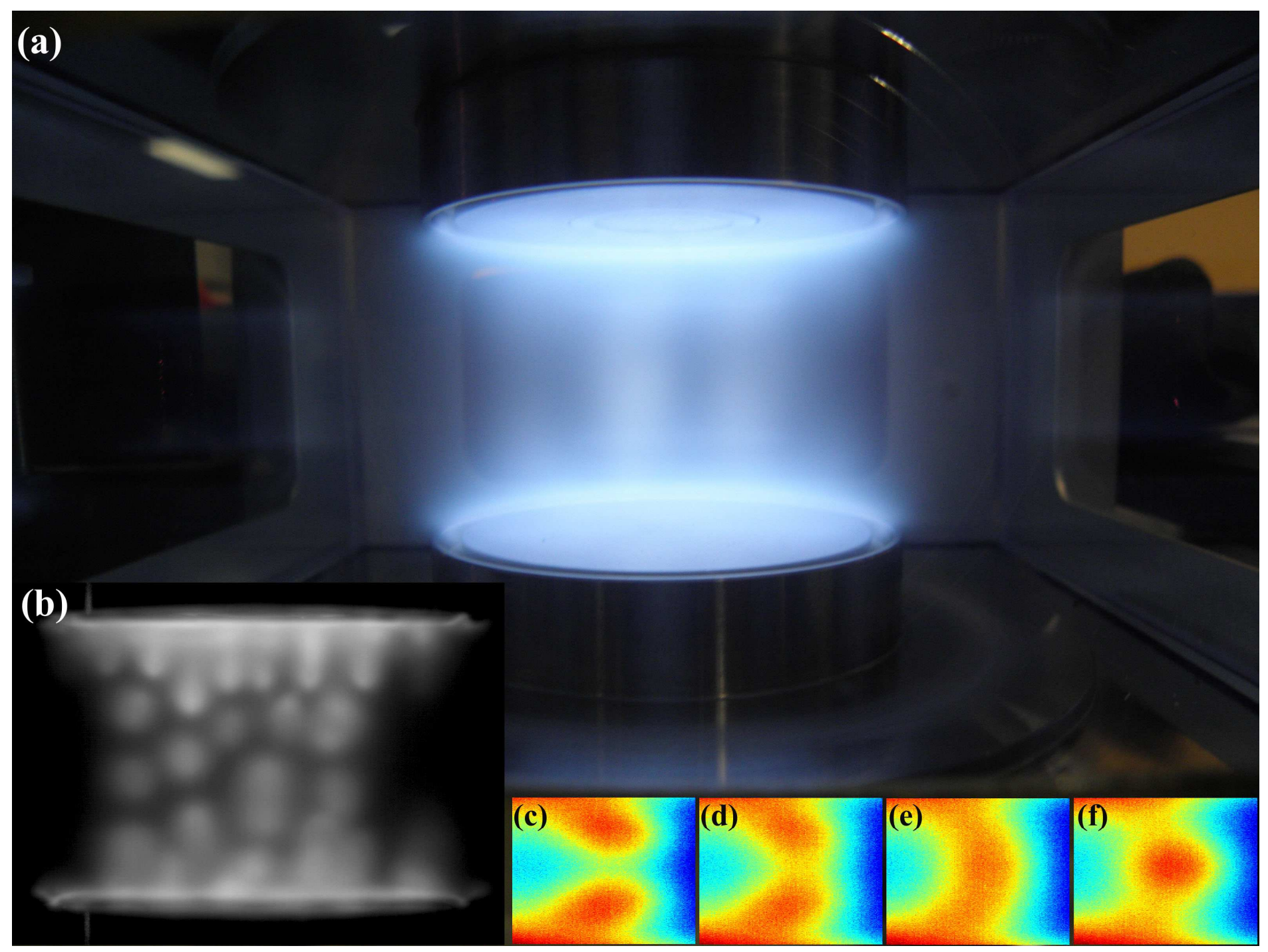

Fig. 1. Plasma instabilities triggered by dust particle formation, (a) Plasma glow emission observed with a standard color camera showing striation like patterns ( $3 \mathrm{~cm}$ gap between the electrodes), (b) High-speed imaging at $8000 \mathrm{fps}$ evidencing the existence of many small bright plasma regions, called plasmoids, interacting with each other, (c)-(f) Merging of two plasmoids (zoom in false colors, image size $1.8 \mathrm{~cm}$ height and $1 \mathrm{~cm}$ width) recorded at $16000 \mathrm{fps}$.

Abstract - Low frequency instabilities are easily obtained in dusty plasmas formed using reactive gases or material sputtering. These unstable phenomena can be characterized by complex and impressive features affecting the plasma glow luminosity. In this paper, we report on a particular phase of an instability where moving bright plasma spots are observed in between the electrodes of a capacitively coupled radio-frequency discharge in Krypton. These plasmoids show complex behaviors like mutual interactions consisting in their merging or splitting.

Index Terms - Complex plasma, dusty plasma, dust particle growth, instabilities, plasmoids.
Formation of dust particles in low pressure rf plasmas is of high interest in a wide variety of scientific fields. Indeed, these media are encountered in astrophysics (for example in some planetary atmospheres), in fusion devices (where the wall erosion is the source of dust) and in industry (where dust particles are undesired in microelectronics but of interest in nanotechnology or in new material design). The production of dust particles in a plasma has a strong influence on the plasma properties. The electrical charging of these "floating probes" strongly disturbs 
the plasma equilibrium leading to unstable phenomena that can be easily visualized on the plasma glow emission.

In this paper, dust particles are grown in the PKENefedov reactor $[1,2]$, a relatively small chamber (electrode diameter of $4 \mathrm{~cm}$, gap of $3 \mathrm{~cm}$ ), originally designed to study 3D plasma crystals, phase transitions and wave propagation under microgravity conditions on board the International Space Station. The present experiments were performed on ground in a $\mathrm{Kr}$ plasma created at a pressure around 1.5 mbar with a power of 3 W. Carbonaceous molecules, sputtered from a polymer layer (melamine formaldehyde) deposited on the electrodes, give birth to dust particles through several chemical and physical reactions. During their growth, dust particles induce low frequency (from a few to a few hundreds $\mathrm{Hz}$ ) instabilities that are observed thanks to high speed imaging at a few thousands frames per second (fps).

These unstable phenomena can be characterized by the appearance of small (a few $\mathrm{mm}$ ) bright plasma spots that we formerly called plasma spheroids [3-6] but now we will use the more widespread term plasmoids [7, 8]. These plasmoids originate from the electrodes and propagate through the discharge center following complex trajectories partly due to their mutual interactions. The global effect on the plasma is shown in Fig. 1(a) taken with a classical 24 fps color camera system. Instabilities appear like vertical striations of the plasma glow but no clear plasmoids can be evidenced. The complexity and the real structure of the instability can only be revealed thanks to high speed imaging as shown in Fig. 1(b) taken at 8000 fps. This insert clearly reveals the existence of small bright plasma regions emerging from the electrodes and propagating in the electrode gap. Their origin could be related to the guard rings surrounding the electrodes and creating a small disturbance of the local electric field $[3,8]$. Most of the plasmoids move away from their place of birth in direction of the facing electrode with typical speeds of about a few $\mathrm{m} / \mathrm{s}$. When no other plasmoid is on their way, they can move following clear lanes as shown by some vertical alignments. Nevertheless, when another plasmoid is in the close vicinity, complex interactions are observed. Their respective trajectories are modified and horizontal displacements (parallel to the electrodes) are obtained.

A more surprising behavior is encountered when two plasmoids get closer and merge [5] as shown in Fig. 1(c)-(f). This unexpected feature is really a merging process with the disappearance of both plasmoids and the birth of a new one in between the two originally isolated plasmoids. The reverse situation is also observed with the splitting of a plasmoid into two parts [5]. Both of these interactions open very interesting questions on the underlying physical mechanisms (electrostatic repulsion or attraction?). Evidencing a corresponding signature in the measurement of the discharge characteristics (discharge current for example) could improve our understanding of this phenomenon.

It is very difficult to directly relate these plasmoids with the dust component in the plasma. Indeed, up to now, we only observed them in high dust density conditions, but it is experimentally not possible to verify if these plasmoids contain dust particles. At this stage of the growth, dust particles are too small (less than a hundred $\mathrm{nm}$ ) and detecting laser light scattering at high speed is difficult due to the small amount of collected light. Considering the obtained plasmoids as small voids could be an interesting perspective. A void is a dust-free region [9] usually appearing in the center of a dust cloud and is the subject of many experimental and theoretical works.

In this paper, we presented a visually impressive instability occurring in dusty plasmas. The study of these small well-delimited plasma regions could be of potential interest beyond the field of dusty plasmas.

\section{ACKNOWLEDGMENTS}

The authors would like to thank the Max Planck Institute for Extraterrestrial Physics, Garching, Germany, for the PKENefedov chamber.

\section{REFERENCES}

[1] A. P. Nefedov et al., "PKE-Nefedov: Plasma crystal experiments on the international space station" New J. Phys. 5, 33 (2003).

[2] M. Mikikian et al., "Formation and Behavior of Dust Particle Clouds in a Radio-Frequency Discharge: Results in the Laboratory and under Microgravity Conditions", New J. Phys. 5, 19 (2003)

[3] H. Tawidian, M. Mikikian, L. Couëdel, T. Lecas, "Plasma inhomogeneities near the electrodes of a capacitively-coupled radio-frequency discharge containing dust particles", Eur. Phys. J. Appl. Phys. 56, 24018 (2011)

[4] M. Mikikian, L. Couëdel, Y. Tessier, L. Boufendi, "Carousel Instability in a Capacitively-Coupled RF Dusty Plasma", IEEE Trans. Plasma Sci. 39, 2748 (2011)

[5] M. Mikikian, H. Tawidian, T. Lecas, "Merging and Splitting of Plasma Spheroids in a Dusty Plasma", Phys. Rev. Lett. 109, 245007 (2012)

[6] H. Tawidian, T. Lecas, M. Mikikian, "Zoom into dusty plasma instabilities", IEEE Trans. Plasma Sci. 41, 754 (2013)

[7] M. Chesaux, A.A. Howling, Ch. Hollenstein, "Funnelling of rf current via a plasmoid through a grid hole in an $\mathrm{rf}$ capacitive plasma reactor", Plasma Sources Sci. Technol. 22, 055006 (2013).

[8] J. Schulze, D. Luggenhölscher, U. Czarnetzki, "Instabilities in capacitively coupled radio-frequency discharges", IEEE Trans. Plasma Sci. 36, 1402 (2008)

[9] J. Goree, G.E. Morfill, V.N. Tsytovich, S.V. Vladimirov, "Theory of dust voids in plasmas", Phys. Rev. E 59, 7055 (1999) 